\title{
Promoting Intergenerational Engagement Within the College Classroom: Faculty Training Needs
}

\author{
Afeez A. Hazzan ${ }^{1}$, Kristin Heffernan ${ }^{2}$, Jason Dauenhauer ${ }^{2}$ \\ ${ }^{1}$ Department of Healthcare Studies, State University of New York at Brockport, USA. \\ ${ }^{2}$ Department of Social Work, State University of New York at Brockport, USA.
}

\begin{abstract}
Institutions of higher education are increasing efforts to focus on ways to meet the growing needs of older adult learners. Many institutions are addressing these needs by joining the Age-Friendly University (AFU) Global Network. Affiliated institutions are required to promote intergenerational learning to facilitate the reciprocal sharing of expertise between learners of all ages. However, these institutions will need to provide instructors with the training to ensure that intergenerational engagement is being actively fostered. In this study, we examine the perspectives of faculty members who have opened their classrooms to older adult auditors. The research question was: What types of training do faculty recommend to promote intergenerational engagement in the classroom? In-depth face to face interviews were conducted with 27 faculty members. Qualitative content analysis of the data yielded the following four themes: 1) Provide accessible training to teach faculty their role 2) Educate faculty about the importance of becoming aware of generational time periods/context 3) Learn to approach auditors with a mindset that they are adults and have had careers/experiences, and 4) Train faculty on how to foster discussion. These findings show a need for training focusing on intergenerational curricular and multigenerational classroom management.
\end{abstract}

Keywords: Intergenerational learning; multigenerational learning; engagement; faculty training; Age-Friendly University; in-depth interviews. 


\section{Introduction}

Institutions of higher education are increasing efforts to focus on ways to meet the growing needs of older adult learners within their respective communities. Colleges and universities are not only poised to create and foster opportunities for continued learning and engagement, career training, and community service for this aging demographic, but for traditionally-aged students as well (Montepare, 2019). Enhancing students' levels of aging literacy and improving attitudes toward aging are issues of great importance as people continue to live and work longer than ever (Whitborne \& Montepare, 2017). One way of doing this is by promoting intergenerational learning in multigenerational classrooms.

Growing numbers of colleges and universities are formalizing their commitment to address these needs by joining the Age-Friendly University (AFU) Global Network. This initiative presents a series of ten principles designed to help higher education institutions develop more age-friendly programs and policies (Dublin City University, 2020 ; O'Kelly; 2015).

Principle Four for the AFU initiative calls for the promotion of intergenerational learning to facilitate the reciprocal sharing of expertise between learners of all ages. This type of learning can be generally described as methods to promote meaningful exchanges of information, perspectives, and learning opportunities between members of older and younger generations. More specifically, Sanchez and Kaplan (2014) define intergenerational learning as "learning between generations stemming from an awareness of differences amassed through individual and group affiliation to diverse generational positions" (p. 475). These authors clarify that 'multigenerational' classrooms are those learning environments in which there are learners from more than one generation present. However, intergenerational learning is specific to the exchanges or interactions between the generations. This point is critical to the success of Principle Four as the course instructor and respective pedagogy of the course have significant influence on the opportunities, promotion, and support of intergenerational engagement.

In a recent study exploring the role of faculty in fostering intergenerational learning, findings revealed that while instructors identified benefits of having an older adult learner in the classroom, they did not change their teaching style or pedagogy to foster intergenerational learning (Heffernan et al., 2019). There was also evidence that some faculty did not see it as their responsibility to provide support for older learners, but that the older adult should seek assistance, or the institution should provide more support to address their learning needs.

As more institutions of higher education work toward adopting and implementing the AFU principles, especially Principle Four, these institutions not only require buy-in from faculty, administrators, and community stake-holders, but need to provide instructors with the resources and ongoing assessment to ensure that intergenerational engagement is being actively fostered, cultivated, and recognized within all courses (Andreoletti \& June, 2019). 
In this study, we examine the perspectives of faculty members who have opened their classrooms to older adult auditors - those who can participate in a course, but do not receive college credit. The primary research question is: What types of training do faculty recommend to promote intergenerational engagement in the classroom? This research builds upon the initial work published by the authors (Heffernan et al., 2019). It involves in-depth face to face interviews with faculty members about their experiences.

\section{Materials and Methods}

\subsection{Context of the study}

In 2016, a medium-sized public liberal arts college in New York State embarked on an initiative to engage community-dwelling older adults in the classroom as 'auditors.' Auditing allows an individual to register for a course, engage in class learning activities as much or as little as desired, without the receipt of college credit. The State University of New York (SUNY) allows state residents aged 60+ to audit any college course for free as long as they have permission from the course instructor and there is space in the class (SUNY, 1992). While some SUNY institutions charge a nominal registration fee for auditing, there is no fee at the authors' institution. Other benefits associated with auditing include reduced-rate parking, creation of a college email account and access to all college technology, library privileges, and membership discounts for the college fitness center.

Each semester, the College's Director of Multigenerational Engagement works with faculty across campus to gain permission to add a limited number of 'seats' to select face to face classes for older adult auditors; between 30-40 courses are promoted each semester. This list is disseminated in the form of a brochure that is mailed to community members and alumni and is also available electronically. Potential auditors then register for the college's Lifelong Learning Orientation where they register for 1-2 classes on a first-come first served basis and participate in a 'tech talk' to assist auditors with accessing college email and technology as well as other supportive services. The orientation also covers various educational programs offered by the college that are open to lifelong learners and community members. Prior to 2016, approximately six older adults enrolled as auditors. Auditing was not promoted by the college and tended to be limited to retired faculty familiar with college registration procedures. Since promotion of the program, enrollment has increased dramatically. In the 2019-2020 academic year, over 80 older adults have enrolled in courses.

\subsection{Study design}

This paper is based on the analysis of qualitative data collected from faculty member interviews conducted between February-May 2019. The purpose was to collect in-depth information from faculty who had granted permission for an older adult to enroll as an auditor 
in at least one of their courses since the fall 2016 semester. A semi-structured interview guide was developed to collect demographic information from faculty (e.g., age, gender, department, rank, etc.), to inquire specifically about the faculty member's perceived benefits and challenges associated with having older adults in the college classroom, determining what levels of intergenerational learning may be taking place, and to identify best practices to foster intergenerational engagement.

\subsection{Participants}

Based on a report from the college's registrar, a total of 43 faculty members had at least one older adult auditor enrolled in at least one of their courses between Fall 2016 and Spring 2019. Each of these faculty members were sent an email from the Director of Multigenerational Engagement describing the interview study and apprising their interest in being interviewed by a graduate assistant. If they were interested in participating, their contact information was sent to the graduate assistant who scheduled a convenient day/time to interview the faculty member in their respective offices. During this meeting, participants were provided with a letter of informed consent that was reviewed by the graduate assistant. Following consent, interviews were recorded and transcribed using a phone-based application entitled 'Otter' (Otter, 2019). This research project was reviewed and approved by the college's Institutional Review Board (IRB).

\subsection{Data analysis}

Data from the face-to-face interviews with faculty members were analyzed using qualitative content analytic approach. As an analytic tool for verbal data, qualitative content analysis makes it possible to summarize large amounts of text into themes or categories that represent similar meanings (Sandelowski, 2010). This methodological approach was utilized for this study because of its usefulness in gaining detailed understanding of the topic being investigated (Hsieh \& Shannon, 2005). Specifically, qualitative content analysis was useful in facilitating the development of knowledge regarding the types of intergenerational engagement taking place in the classroom. It also helped in shedding light on the faculty reports of best practices regarding training needs.

To begin the content analytic process, the data obtained from the face-to-face interviews with faculty members were transcribed verbatim using Otter (Otter 2019). The authors independently read all the interview transcripts to achieve robust understanding of the data obtained from the interviews with the faculty members who participated in this study. Following the completion of the data immersion process, each of the three authors wrote down words or codes from each interview that seemed to capture important thoughts or concepts. The three authors met periodically to compare codes, finalize the initial coding 
scheme, and to sort the codes into emergent themes that represent the key findings from the face-to-face interviews with faculty members.

\section{Results}

Table 1 presents participants' demographic information including rank, education level, and years teaching. A total of 27 of the 43 faculty participated in this study for a $62 \%$ response rate. Participants represented ten different academic departments. Nearly all described their race/ethnicity as white/Caucasian $(89 \%, n=24)$ and most were female $(67 \%, n=18)$. The overall teaching experience ranged from 1 year to 49 years with an average of 15.6 years (SD: 8.76). The average age of faculty participants was 49.2 years (SD: 10.6) and ranged from 30 to 74 years.

Research Question: What types of training do faculty recommend to promote intergenerational engagement in the classroom?

Faculty interviewed for this study articulated the importance of adequate training in promoting intergenerational engagement within the college classroom. Faculty training needs were organized into four themes: 1) Provide accessible training to teach faculty their role in fostering intergenerational learning 2) Educate faculty about the importance of becoming aware of generational time periods/context of both auditors and the students, 3) Learn to approach auditors with a mindset that they are adults and have had careers/experiences, and 4) Train faculty on how to foster discussion, particularly with older adult learners present.

Supporting Quotes for Theme 1: Provide accessible training to teach faculty their role in fostering intergenerational learning

"I would love to have other professors...ones that have had really good experiences, like what are the ways to cultivate that. Kind of like, you know, a panel discussion of the people that have had a lot of these students." (Interview 12)

"If anything, I would suggest that, you know, you could have a webinar or something for faculty that might help them to understand what their roles and responsibilities are. But that's very straight." (Interview \#7)

Supporting Quotes for Theme 2: Educate faculty about the importance of becoming aware of generational time periods/context of both auditors and traditional students.

“...perhaps some training on diversity and thinking about, especially for classes, that have controversial material that might be sort of controversial having students at different generations" (Interview \#4).

"The professor should be aware of the life experiences and educational experiences in their discipline were likely to be for the adult learners." (Interview \#19) 
"I have had a couple of times where auditors have maybe said something that is generationally different from their time to how students behave now. And then I think it takes a little while for students to probe why someone said something that they think is maybe inappropriate and understand the motives of the auditor. So guiding that process along is, I think, how I dealt with it..." (Interview 28).

Supporting Quotes for Theme 3: Learn to approach auditors with mindset that they are adults and have had careers/experiences,

"Our job is to tap into what auditors can bring and that is life experience that even we, as professors, don't necessarily have.” (Interview \#17)

“...I think, you know, anytime, even in a lecture setting if you can involve people and have them relate their own personal experiences, some you know, have so much to inform the topic matter, they've experienced it, they lived it" (Interview \#2)

Supporting Quotes for Theme 4: Train faculty on how to foster discussion, particularly with older adult learners present in the classroom

I think just being able to foster discussion. I mean, I think that that is how we can be better trained [talking about the differences between generations] (Interview \#9).

“...So some kind of at least discussion and sort of techniques for making sure that students, younger students in the class aren't intimidated, but are actually inspired...by viewpoints that are expressed by someone from a much older generation." (Interview \#11) 
Table 1. Participant Demographic Data.

\begin{tabular}{|c|c|c|c|}
\hline & $\mathbf{M}$ & (SD), \% & $\mathbf{n}$ \\
\hline Age & 49.2 & $(10.6)$ & 26 \\
\hline \multicolumn{4}{|l|}{ Gender } \\
\hline Female & 67 & & 18 \\
\hline Male & 33 & & 9 \\
\hline \multicolumn{4}{|l|}{ Race/Ethnicity } \\
\hline White non-Hispanic & 89 & & 24 \\
\hline Hispanic & 4 & & 1 \\
\hline Asian & 4 & & 1 \\
\hline Other & 4 & & 1 \\
\hline \multicolumn{4}{|c|}{ Education/Highest Degree } \\
\hline Doctorate & 78 & & 21 \\
\hline Masters & 19 & & 5 \\
\hline Other & 4 & & 1 \\
\hline Years teaching & 15.6 & (8.7) & 27 \\
\hline \multicolumn{4}{|l|}{ Academic Rank } \\
\hline Professor (full) & 7 & & 2 \\
\hline Associate & 59 & & 18 \\
\hline Assistan & 15 & & 4 \\
\hline Lecturer & 7 & & 2 \\
\hline Adjunct & 11 & & 3 \\
\hline
\end{tabular}

\section{Discussion}

In analyzing the narrative responses to the question: What types of training do faculty recommend to promote intergenerational engagement in the classroom?, we uncovered four inter-related themes. In the first theme, faculty appear eager to foster a good experience for all students in their classrooms, however, it was clear that some did not understand how this could look different in a multigenerational classroom. Some indicated that they taught the class as usual, while others acknowledged that having familiarity with the tenets underpinning intergenerational learning would be helpful (Corrigan, et al., 2013; Dauenhauer et al., 2021; Heffernan et al., 2019). The other three themes identified, spoke to the importance of first understanding that generational differences exist, and then developing skills to use these differences to help students learn, and accept, that there may be more than 
one way to interpret the same content; bringing up the idea of multiple realties. Biggs and Lowestien (2011) also argue the importance of allowing for multiple perspectives as a way to increase generational intelligence. They define generational intelligence "as the ability to reflect and act, which draws on an understanding of one's own and other's life-course, family and social history, placed within social and cultural context" (Briggs \& Lowenstein, 2011, p. 2). Being able to recognize the importance of differing or alternative perspectives, depending on where someone is at with regards to their generational development, appears to be equally important as understanding how to foster culturally sensitive discussions between the different generations. Additionally, many faculty were aware of the knowledge and experience brought by the auditors, however, they were not always sure how to use this experience without making the traditional students feel intimidated. Future training for faculty teaching in multigenerational classrooms should include helping them to understand the principles as well as benefits of intergenerational learning. Further, helping faculty understand the concept of generational intelligence may help facilitators reflect on their own life course development, and how this influences their way of thinking about the content they teach in order to better understand the perspective of those from a different generation. Issues of how to use the expertise of older adults and still allow equal time for younger generations to discuss their experiences without feeling intimidated are not new. Future training for faculty interested in learning how to promote intergenerational learning must focus on both intergenerational curricular design as well as multigenerational classroom management (Montepare \& Farah, 2018; Dauenhauer et al., 2021).

\section{References}

Andreoletti, C. \& June, A. (2019) Coalition building to create an Age-Friendly University (AFU). Gerontology \& Geriatrics Education, 40 (2), 142-152, DOI: 10.1080/02701960.2019.1572008

Biggs, S. \& Lowenstein, A. (2011). Generational intelligence: A critical approach to age relations. Routledge

Corrigan,T., McNamara, G. \& O'Hara, J. (2013). Intergenerational learning: A valuable learning experience for higher education students, Egitim Arastirmalari, Eurasian Journal of Educational Research, 52, 117-136.

Dauenhauer, J., Hazzan, A., Heffernan, K., \& Milliner, C. M. (2021). Faculty perceptions of engaging older adults in higher education: The need for intergenerational pedagogy. Gerontology \& geriatrics education, 1-22. Advance online publication. https://doi.org/10.1080/02701960.2021.1910506

Dublin City University, (2020, November, 2). Age-friendly university. https://www.dcu.ie/agefriendly/principles-age-friendly-university

Heffernan, K., Cesnales, N., Dauenhauer, J. (2019). Creating intergenerational learning opportunities in multigenerational college classrooms: Faculty perceptions and 
experiences. Gerontology \& Geriatrics Education, https://doi.org/10.1080/02701960.2019.1613235

Hsieh H.F. \& Shannon S.E. (2005). Three approaches to qualitative content analysis. Qualitative Health Research, 15 (9), 1277-1288.

Montepare, J.M. (2019). Introduction to the special issue-Age Friendly Universities (AFU): Principles, practices, and opportunities. Gerontology and Geriatrics Education, 40 (2), 139-141. https://doi.org//10.1080/02701960.2019.1591848

Montepare \& Farah (2018). Talk of Ages: Using intergenerational classroom modules to engage older and younger students across the curriculum. Gerontology \& Geriatrics Education, 39, 385-394, https://doi.org/10.1080/02701960.2016.1269006

O'Kelly, C. (2015). Age-friendly university annual report. Retrieved from https://www.dcu.ie/sites/default/files/agefriendly/afu_annual_report_complete.pdf

Otter. (2019). Otter voice meeting notes. Retrieved from: https://otter.ai

Sanchez, M., \& Kaplan, M. (2014). Intergenerational learning in higher education: Making the case for multigenerational classrooms. Educational Gerontology, 40, 473-485. https://doi.org/ 10.1080/ 03601277.2013.844039

Sandelowski M. (2010). What's in a name? Qualitative description revisited. Research in Nursing \& Health, 33, 77-84.

Whitbourne, S. K., \& Montepare, J. M. (2017). What's holding us back? Ageism in higher education. In T. Nelson (Ed.), Ageism: Stereotyping and prejudice against older persons (2nd ed., pp. 263-290). MIT Press 